\title{
(6) OPEN ACCESS \\ Predicting human papillomavirus vaccination behaviour among adolescent girls in England: results from a prospective survey
}

\author{
Harriet L Bowyer, ${ }^{1}$ Alice S Forster, ${ }^{2}$ Laura A V Marlow, ${ }^{3}$ Jo Waller ${ }^{4}$
}

\begin{abstract}
${ }^{1}$ Research Assistant, Research Department of Epidemiology and Public Health, Cancer Research UK Health Behaviour Research Centre, University College London, London, UK

${ }^{2}$ Research Fellow, Research Department of Epidemiology and Public Health, Cancer Research UK Health Behaviour Research Centre, University College London, and Department of Primary Care and Public Health Sciences, King's College London, London, UK

${ }^{3}$ Research Fellow, Research Department of Epidemiology and Public Health, Cancer Research UK Health Behaviour Research Centre, University College London, London, UK ${ }^{4}$ Senior Research Associate, Research Department of Epidemiology and Public Health, Cancer Research UK Health Behaviour Research Centre, University College London, London, UK
\end{abstract}

\section{Correspondence to Dr Jo Waller, Research Department of Epidemiology and Public Health, Cancer Research UK Health Behaviour Research Centre, University College London, Gower Street, London WC1E 6BT, UK; \\ j.waller@ucl.ac.uk}

Received 7 January 2013 Revised 26 April 2013 Accepted 22 May 2013 Published Online First 31 July 2013

To cite: Bowyer $\mathrm{HL}$, Forster AS, Marlow LAV, et al. J Fam Plann Reprod Health Care 2014:40:14-22.

\section{ABSTRACT \\ Background To maximise the benefits of human papillomavirus (HPV) vaccination, uptake needs to be high. We examined psychosocial predictors of HPV vaccine uptake and the association between vaccine intention and uptake 1 year later in adolescent girls (aged 16-17 years) in England.}

Method Adolescent girls in the catch-up cohort were recruited from colleges in the South East of England in 2009 and 2010. Participants completed a questionnaire 6 months before $(n=606)$ and 6 months after $(n=214)$ being offered the vaccine, which assessed vaccine intention, vaccine uptake, demographics and attitudes based on the Health Belief Model and Theory of Planned Behaviour.

Results A number of demographic and psychological factors, including intention, showed associations with vaccine uptake in univariable analyses. In multi-variable analyses, only ethnicity was independently associated with vaccine uptake. Participants from Black or 'Other' ethnic backgrounds were less likely to have received the HPV vaccine than White participants.

Conclusions More research is needed to help understand variation in vaccine coverage between ethnic groups.

\section{INTRODUCTION}

Since September 2008, a free vaccination programme has been available for 1213-year-old females in the UK, offering protection against the two high-risk types of human papillomavirus (HPV) responsible for $\sim 70 \%$ of cervical cancers. ${ }^{1}{ }^{2}$ A 'catch-up' programme was available for older girls (aged 14-18 years) between 2008 and 2011. Most girls in the 'catch-up' cohort were offered the vaccine through primary care $60 \%$ in
Key message points

Ethnicity predicted human papillomavirus (HPV) vaccine uptake among girls in the 'catch-up' cohort.

- More research is needed to help understand ethnic differences in HPV vaccine coverage.

$2008 / 2009$ and $57 \%$ in $2009 / 2010)^{3}{ }^{4}$ or at their educational institution.

In the first 2 years of the programme in England, uptake for all three doses in the routine cohort (12-13-year-olds) reached $80 \%$ and $76 \%$, respectively. Uptake for 17-18-year-olds was lower, with 32\% and 39\% receiving three doses in the first and second year of the catch-up programme. ${ }^{3}$ For the benefits of the vaccination programme to be maximised, $80 \%$ coverage is needed to achieve a $63 \%$ reduction in cervical cancer. ${ }^{5}$ Belowoptimal HPV vaccination coverage rates among 17-18-year-olds may have been due to structural (e.g. invitations), environmental (e.g. media coverage) and individual-level factors (e.g. sociodemographics and beliefs). ${ }^{6}$ This study focused on exploring the individual-level predictors of HPV vaccine uptake, drawing on psychological theories of health behaviour.

Much research has focused on intentions to receive the HPV vaccine, with elements of the Health Belief Model $(\mathrm{HBM})^{7}$ and Theory of Planned Behaviour (TPB $)^{8}$ explaining some variance in intentions to receive the vaccine (or consenting for a child to do so). In the context of HPV vaccination, the 
HBM suggests that vaccine intention and receipt can be predicted by an individual's perceived severity of and susceptibility to HPV or cervical cancer, their beliefs about the benefits of and barriers to being vaccinated, and cues to action (e.g. a doctor's recommendation). The TPB argues that attitudes, subjective norms (beliefs about what others would approve of the person doing coupled with their motivation to comply with this person's opinion) and perceived behavioural control (an individual's perception of the difficulty/ease of receiving the vaccine) predict intentions to receive the vaccine and that intention predicts behaviour. A systematic review of 28 studies ${ }^{9}$ found that perceived susceptibility, perceived effectiveness of the vaccine and a physician's recommendation predicted parental intentions to have daughters vaccinated against HPV. Beliefs about susceptibility, ${ }^{10-12}$ severity, ${ }^{11}{ }^{13}$ benefits, ${ }^{10}{ }^{11}$ subjective norms ${ }^{10} 1314$ and attitudes ${ }^{10}{ }^{14}$ have all shown associations with young women's intentions to receive the vaccine.

Several studies have found that intention to receive the HPV vaccine is a predictor of vaccine uptake. ${ }^{14-16}$ A limited amount of research has focused on other psychological predictors of girls' and young women's uptake, but subjective norms, ${ }^{17}{ }^{18}$ barriers, ${ }^{15} \quad 1920$ benefits ${ }^{14}$ and perceived susceptibility ${ }^{14}{ }^{15}$ have all been found to be associated with HPV vaccine uptake, although some of this evidence is from cross-sectional studies. A longitudinal study considering psychological factors found that intention, perceived barriers and anticipated regret predicted vaccination initiation (in addition to not needing more information and not being a born-again Christian), ${ }^{21}$ however this study measured parents' beliefs and not those of the girls themselves. Research has also shown that mothers talk about sex when discussing the HPV vaccine with their daughters $^{22}$ and that this communication with daughters about sex is associated with vaccine uptake. ${ }^{23}$

To our knowledge, there have been no prospective studies investigating the relationship between girls' intentions to receive the vaccine and uptake in the UK, and only one study focusing on predictors of vaccine uptake. This study found support for the relationship between subjective norms and HPV vaccine uptake. ${ }^{18}$ We report a longitudinal study of female students in the second year of the 'catch-up' programme that aimed to: (1) establish predictors of vaccine uptake and (2) measure the association between intention to have the HPV vaccine and uptake 1 year later.

\section{METHODS}

In March 2009, girls in school Year 12 (aged 1617 years) were recruited from eight further education colleges in the South East of England. These young women were due to be offered the HPV vaccine for the first time in September 2009.
Box 1 Brief information about human

papillomavirus and the vaccine, contained in the questionnaire

Human papillomavirus (HPV) is a very common infection involved in most cervical cancers. It is transmitted via skin-to-skin contact, most commonly during sexual activity. A vaccine has been developed that protects against this infection. Next school year you will be offered the HPV vaccine.

A researcher visited the colleges, explained the study to all girls in attendance and gave the girls a baseline questionnaire. A follow-up questionnaire was given to girls from five of the original colleges in March 2010, by which time participants had been offered free HPV vaccination as part of the English HPV immunisation programme. Dependent on the procedures of local primary care trusts, girls were either offered the vaccine in college or at their general practice or local pharmacy.

We were unable to re-recruit girls from three of the baseline colleges; one withdrew from the study and two would not allow us to replicate the baseline recruitment procedures. In addition, as adolescents in England are not required to stay in education after the age of 16 years, some of the girls recruited at the remaining five colleges had left before the follow-up.

Both questionnaires were paper-based and selfadministered and consent was inferred from the completion of the questionnaire. Other aspects of the study have been described elsewhere. ${ }^{24}$

\section{Materials and measures}

At baseline, the Department of Health had published an HPV vaccine information leaflet for young women, but it was unknown whether all participants had received this leaflet. The questionnaire therefore contained brief information about HPV and the vaccine (see Box 1).

\section{Dependent variable}

Self-reported HPV vaccine receipt was assessed at both time points. At baseline, participants were asked 'Have you already received the HPV vaccine?' ('Yes/ No'); this was unlikely unless they had received the vaccine privately. At follow-up, participants were asked to select the option that best described them from a pre-defined list ('I have received all three doses of the HPV vaccine'; 'I have received one or two doses of the HPV vaccine and will complete the course of injections'; 'I have received one or two doses of the HPV vaccine and will not complete the course of injections'; 'I have been offered the HPV vaccine but I haven't had it'; 'I have been offered the HPV vaccine but have decided not to have it'; and 'I have not been offered the HPV vaccine'). Individuals 
who had received at least one dose of the vaccine were coded as 'vaccinated'; all other individuals were coded as 'unvaccinated'.

Independent variables

All independent variables were measured at baseline.

Intention to accept the HPV vaccine was measured using two items recommended by Sheeran and Abraham: ${ }^{25}$ 'I will try to have the HPV vaccine' and 'I intend to have the HPV vaccine' (five-point scale: 'Strongly disagree' to 'Strongly agree', scored from 0 to 4). These two items correlated highly $(r=0.87)$ and were summed to give an intention score. The score was skewed so a binary outcome was created using a median split, with those scoring $0-5$ classified as having 'low intention' and those scoring 6-8 classified as having 'high intention' to receive the HPV vaccine.

Demographic/cultural characteristics were assessed. Participants reported their ethnicity, religion, whether anyone close to them had been diagnosed with cancer and/or cervical cancer and whether they smoked. Household income was indexed by eligibility for the Educational Maintenance Allowance (EMA), with individuals classified as 'eligible' or 'not eligible'. [NB. EMA was a financial scheme available before 2010 to students aged between 16 and 19 years whose parents met a certain level of taxable income. Students received EMA if their household income was under $£ 30810$ per year. Students with a household income exceeding $£ 30810$ per year were not entitled to EMA.] Participants reported lifetime number of sexual partners $(\geq 1$ sexual partners coded as 'sexually active' and no sexual partners coded as 'not sexually active'). Sexually active participants were asked for their age at sexual debut, with responses coded as ' $\geq 16$ years' or ' $\leq 15$ years'. These questions were adapted from the National Surveys of Sexual Attitudes and Lifestyles 2000. ${ }^{26}$

Knowledge of HPV was assessed by asking participants whether 17 statements about HPV and the HPV vaccine were 'True' or 'False' using a validated measure ${ }^{27}$ : a total knowledge score was derived by summing the number of correct responses.

Vaccine attitude was assessed using the sum score on three items: 'Do you think that vaccinations are necessary to prevent certain diseases?', 'Do you think that it is important to have vaccinations?' and 'Do you think that vaccinations in general are safe?' (five-point scale: 'Definitely not' to 'Yes, definitely'). These items were adapted from a previous study. ${ }^{28}$

Needle fear was assessed using a single-item: 'Are you scared of needles?' (five-point scale: 'Not at all scared' to 'Very scared').

Parental acceptance of the vaccine ('My parents will let me have the vaccine') was assessed using a singleitem on a five-point scale ('Strongly disagree' to 'Strongly agree').

Normative beliefs focusing on friends ('My friends will think I should have the HPV vaccine') and parents
('My parents will think I should have the HPV vaccine') were measured using single-items on five-point scales ('Strongly disagree' to 'Strongly agree'). ${ }^{29}$

Vaccine safety was assessed using a single-item ('Do you think that the HPV vaccine is safe?') on a fivepoint scale ('Definitely not' to 'Yes, definitely'). ${ }^{28}$

Vaccine effectiveness in preventing cervical cancer, HPV infection and sexually transmitted infections (STIs) was measured on a five-point scale ('Strongly disagree' to 'Strongly agree') using three single items developed by Witte et al. ${ }^{30}$ and widely used in HPV studies. $^{11} 31$

Perceived severity of HPV and of cervical cancer was assessed by summing scores on a three-item measure developed by Witte et al. ${ }^{30}$ Each item was assessed on a five-point scale ('Strongly disagree' to 'Strongly agree').

Perceived susceptibility to HPV and cervical cancer were measured using a single-item ('If I never have the HPV vaccine I would feel very vulnerable to $\mathrm{HPV} /$ cervical cancer in the future') on a five-point scale ('Strongly disagree' to 'Strongly agree') adapted from a similar item used by Weinstein et al. ${ }^{32}$

Communication with parents about sex was assessed by asking participants whether they had ever talked about sexual intercourse, condoms, contraception or STIs with their parents/guardians ('Yes' $=1$; 'No'/ 'Can't remember' $=0)$. These items were adapted from Hutchinson et al. ${ }^{33}$ Responses were summed to give a total score (0-4).

The means, ranges and Cronbach's $\alpha$ statistics for all continuous variables and scales are reported in Table 1.

Analysis

We used complex samples logistic regression analysis clustering by college to examine predictors of vaccine uptake at follow-up. We ran uni-variable models followed by a multi-variable model including all factors showing significant $(p<0.05)$ associations with uptake in the uni-variable models. The location at which the vaccine was offered to the girls varied across the sample; some girls were offered the vaccine within their college and some had to access it through primary care. Location (college vs primary care) was therefore entered as a covariate for all analyses. Analyses were performed using SPSS V.20. ${ }^{34}$

\section{RESULTS}

\section{Participants}

A total of $93 \%$ of the girls approached at baseline agreed to participate $(n=650 / 697)$. Participants were excluded if their baseline vaccine status was unknown $(n=11)$ or if they had already received the HPV vaccine at baseline $(n=33)$. Complete baseline data were available for 606 participants. Data from baseline and follow-up were matched using participants' postcodes and dates of birth, with 218 (33.5\%) 
Table 1 Description of the sample at baseline and follow-up

\begin{tabular}{|c|c|c|c|c|}
\hline Variables & & & $\begin{array}{l}\text { Baseline }(n=606)^{*} \\
{[\%(n)]}\end{array}$ & $\begin{array}{l}\text { Follow-up }(n=214)^{*} \\
{[\%(n)]}\end{array}$ \\
\hline \multicolumn{5}{|l|}{ Categorical variables } \\
\hline \multicolumn{5}{|l|}{ Ethnicity } \\
\hline White & & & $54.5(330)$ & $65.9(141)$ \\
\hline Asian & & & $18.2(110)$ & 17.8 \\
\hline Black & & & $12.7(77)$ & $3.3 \quad(7)$ \\
\hline Other & & & $11.2(68)$ & $11.7(25)$ \\
\hline \multicolumn{5}{|l|}{ Religion } \\
\hline Christian & & & $40.1(243)$ & $38.3(82)$ \\
\hline None & & & $33.0(200)$ & $36.4(78)$ \\
\hline Muslim & & & $13.4(81)$ & 16.4 \\
\hline Other & & & $11.2(68)$ & $8.4(18)$ \\
\hline \multicolumn{5}{|c|}{ Someone close diagnosed with cancer? } \\
\hline No & & & $35.5(215)$ & $36.4(78)$ \\
\hline Yes & & & $61.6(373)$ & $62.1(133)$ \\
\hline \multicolumn{5}{|c|}{ Someone close diagnosed with cervical cancer? } \\
\hline No & & & $88.4(536)$ & $90.7(194)$ \\
\hline Yes & & & $8.4 \quad(51)$ & $7.9(17)$ \\
\hline \multicolumn{5}{|l|}{ Smoking status } \\
\hline No & & & $77.1(467)$ & $86.4(185)$ \\
\hline Yes & & & $19.8(120)$ & $12.6(27)$ \\
\hline \multicolumn{5}{|l|}{ Entitled to EMA? } \\
\hline No (high-income household) & & & $51.8(314)$ & $62.1(133)$ \\
\hline Yes (low- income household) & & & $44.6(270)$ & $36.0(77)$ \\
\hline \multicolumn{5}{|l|}{ Sexually active } \\
\hline No & & & $56.4(342)$ & $62.1(133)$ \\
\hline Yes & & & $41.3(250)$ & $35.5(76)$ \\
\hline \multicolumn{5}{|l|}{ Age of sexual debut } \\
\hline 16 years and above & & & $20.1(122)$ & 16.4 (35) \\
\hline 15 years and below & & & $20.6(125)$ & $19.2(41)$ \\
\hline \multicolumn{5}{|l|}{ Intention } \\
\hline High & & & $67.2(407)$ & $75.2(161)$ \\
\hline Low & & & $32.8(199)$ & 24.8 \\
\hline Continuous variables & $\alpha$ & Range & Mean (SD) & Mean (SD) \\
\hline HPV knowledge & 0.72 & $0-15$ & $8.00(3.18)$ & $8.87(2.96)$ \\
\hline Positive vaccine attitude & 0.69 & $0-12$ & $9.76(1.85)$ & $10.17(1.45)$ \\
\hline Needle fear & & $0-4$ & $1.82(1.46)$ & $1.63(1.46)$ \\
\hline Parental acceptance & & $0-4$ & $3.13(0.91)$ & $3.28(0.79)$ \\
\hline \multicolumn{5}{|l|}{ Normative beliefs about HPV vaccine } \\
\hline Friends & & $0-4$ & $2.80(0.87)$ & $2.83(0.76)$ \\
\hline Parent & & $0-4$ & $2.91(0.95)$ & $3.02(0.85)$ \\
\hline Vaccine safety & & $0-4$ & $2.66(0.68)$ & $2.78(0.63)$ \\
\hline \multicolumn{5}{|l|}{ Vaccine effectiveness against: } \\
\hline HPV & & $0-4$ & $2.56(0.66)$ & $2.87(0.61)$ \\
\hline Cervical cancer & & $0-4$ & $2.72(0.64)$ & $2.67(0.65)$ \\
\hline Sexually transmitted infections & & $0-4$ & $1.67(0.95)$ & $1.58(1.00)$ \\
\hline \multicolumn{5}{|l|}{ Perceived severity of: } \\
\hline HPV & 0.95 & $0-12$ & $7.60(2.73)$ & $7.73(2.86)$ \\
\hline Cervical cancer & 0.97 & $0-12$ & $10.22(2.30)$ & $10.43(2.17)$ \\
\hline \multicolumn{5}{|l|}{ Perceived susceptibility to: } \\
\hline HPV & & $0-4$ & $2.31(0.87)$ & $2.31(0.88)$ \\
\hline Cervical cancer & & $0-4$ & $2.29(0.87)$ & $2.28(0.84)$ \\
\hline Discussing sex with parents & 0.83 & $0-4$ & $2.14(2.74)$ & $2.20(1.53)$ \\
\hline
\end{tabular}

*Note that $n$ varies slightly between items because of missing data.

EMA, Educational Maintenance Allowance; HPV, human papillomavirus; SD, standard deviation. 
successfully matched. Those who completed the follow-up questionnaire ('completers') differed from those who did not ('non-completers') in terms of ethnicity $(p<0.001)$; participants from Black backgrounds were less likely to be completers than participants from White $(p<0.001)$, Asian $(p=0.001)$ or other ethnic backgrounds $(p=0.006)$. Participants also differed in terms of EMA entitlement $(p=0.003)$; those entitled to EMA were less likely to be completers $(38.7 \%)$ than those not entitled to EMA (50.4\%). Participants were removed from the analysis if they failed to state their vaccine status at follow-up $(n=4)$. Complete data were available for 214 participants; characteristics of the baseline and follow-up samples are shown in Table 1.

\section{HPV vaccine uptake}

At follow-up, $59.8 \%$ of participants had received at least one dose of the vaccine $(n=128 / 214)$. In the 'vaccinated' group, $16.8 \%(n=36)$ had received all three doses, $41.6 \%(n=89)$ had received one or two doses and intended to complete the course, and 1.4\% $(n=3)$ had received one or two doses and did not intend to complete the course. In the 'unvaccinated' group, $16.8 \%(n=36)$ reported having been offered the vaccine but had not yet had it, $7.9 \%(n=17)$ reported refusing the vaccine and $15.4 \%(n=33)$ said they had not been offered the vaccine.

\section{Uni-variable analyses}

Intention to have the vaccine at baseline was significantly associated with having had the vaccine at follow-up $(p=0.021)$. Two thirds of girls $(n=104 /$ $161 ; 64.6 \%)$ with a high baseline intention to receive the vaccine had received at least one dose of the vaccine at follow-up compared with $45.3 \% \quad(n=24 /$ 53) of those with low intention. There were ethnic differences in HPV vaccine uptake, with girls from Asian and 'Other' ethnic backgrounds reporting uptakes of $52.6 \%$ and $32.0 \%$, respectively, compared with $68.1 \%$ in the White group $(p=0.018$ and $p<0.001$, respectively). HPV vaccine uptake also differed by religion; girls who had no religious affiliation reported an uptake rate of $62.8 \%$, compared with $64.6 \%$ in the Christian group $(p=0.002)$. There was no significant difference in vaccine uptake by EMA entitlement, smoking status, cervical cancer or cancer experience, being sexually active, or age of sexual debut (Table 2).

We also examined whether girls' attitudes at baseline predicted whether they had received at least one dose of the HPV vaccine at follow-up (Table 2). Girls who had higher knowledge of HPV and the HPV vaccine at baseline were more likely to have received the vaccine at follow-up $(p=0.027)$. Girls who believed that their parents would let them have the vaccine $(p<0.001)$, and who believed that their friends $(p=0.027)$ and parents $(p=0.012)$ thought they should have the vaccine were more likely to have received it. Girls who believed the vaccine was safe $(p=0.010)$, and effective against cervical cancer $(p=0.046)$ were more likely to have received it. Girls who thought that HPV was severe and that they were susceptible to HPV were more likely to have received the vaccine $(p=0.021$ and $p=0.003$, respectively). Vaccine uptake was not associated with having a positive attitude towards vaccines in general, needle fear, communicating with parents about sex, beliefs about how effective the vaccine is against HPV or STIs, or perceived severity of and susceptibility to cervical cancer.

\section{Multi-variable analysis}

The multi-variable model explained between 14\% and $19 \%$ of the variance in HPV vaccine uptake (Table 2). Only ethnicity remained a significant predictor of HPV uptake in the model $(p=0.030)$; participants who reported coming from Black [odds ratio (OR) $=0.19,95 \%$ confidence interval (CI) $0.04-0.98$ ] or 'Other' $(\mathrm{OR}=0.25,95 \%$ CI $0.07-0.88)$ ethnic backgrounds were significantly less likely to have received the HPV vaccine than White participants.

\section{DISCUSSION}

This prospective study examined the association between demographic and psychological variables measured at baseline, and vaccine uptake measured 1 year later, among girls in the UK HPV vaccination 'catch-up' programme. Ethnicity was the only factor that predicted vaccine uptake in our multi-variable model, which is consistent with previous research linking ethnicity with uptake. ${ }^{35}{ }^{36}$ A meta-analysis of mainly North American studies has reported that young Black women are less likely to initiate HPV vaccination compared to young White women. ${ }^{37}$ In a pilot study carried out before the introduction of the HPV vaccine in the UK, uptake was lower in schools with greater ethnic diversity, ${ }^{38}{ }^{39}$ and analyses of data from the first year of the vaccination programme (routine and 'catch-up' cohorts) also suggest that ethnicity is an important factor in understanding uptake in the UK. ${ }^{35}$ Research from the UK has also suggested that there is lower awareness and acceptability of the HPV vaccine among ethnic minority groups. ${ }^{40}$ Future research should explore factors predicting HPV vaccine uptake within ethnic minority groups. Such research could identify attitudinal targets for interventions aimed at increasing informed uptake of vaccination.

Consistent with social cognition models, ${ }^{7} 8$ vaccine intentions significantly predicted behaviour in the univariable model, highlighting the importance of understanding predictors of intention to promote uptake. Approximately $75 \%$ of participants had high intentions to receive the vaccine, in line with similar studies, ${ }^{13} 14$ and $60 \%$ of participants received the vaccine at follow-up. This figure is broadly similar to the national average of $56 \%$ receiving at least one 
Table 2 Demographic and attitudinal predictors of human papillomavirus vaccine uptake, clustering by college and controlling for location at which the vaccine was offered $\left(n=214^{*}\right)$

\begin{tabular}{|c|c|c|c|c|c|}
\hline \multirow[b]{2}{*}{ Variables } & \multirow[b]{2}{*}{ Vaccine initiated $[\%(n)]$} & \multicolumn{2}{|c|}{ Uni-variable analyses* } & \multicolumn{2}{|c|}{$\begin{array}{l}\text { Multi-variable analysis } \\
(n=204)^{*}\end{array}$} \\
\hline & & OR $(95 \% \mathrm{Cl})$ & $p$ & OR $(95 \% \mathrm{Cl})$ & $p$ \\
\hline \multicolumn{6}{|l|}{ Categorical variables } \\
\hline \multicolumn{6}{|l|}{ Ethnicity } \\
\hline White & 68.1 (96) & 1.00 & & & \\
\hline Asian & $52.6 \quad(20)$ & $0.40(0.21-0.77)$ & 0.018 & $0.54 \quad(0.03-9.03)$ & 0.578 \\
\hline Black & $28.6 \quad(2)$ & $0.17(0.02-1.34)$ & 0.076 & $0.19 \quad(0.04-0.98)$ & 0.048 \\
\hline Other & $32.0 \quad(8)$ & $0.19(0.13-0.29)$ & $<0.001$ & $0.25 \quad(0.07-0.88)$ & 0.038 \\
\hline \multicolumn{6}{|l|}{ Religion } \\
\hline Christian & $64.6 \quad(53)$ & 1.00 & & & \\
\hline None & $62.8(49)$ & $0.90(0.87-0.94)$ & 0.002 & $0.81 \quad(0.62-1.06)$ & 0.096 \\
\hline Muslim & 42.9 (15) & $0.30(0.05-1.95)$ & 0.148 & $0.65 \quad(0.06-6.95)$ & 0.642 \\
\hline Other & $61.1(11)$ & $0.78(0.26-2.38)$ & 0.575 & $1.59(0.09-27.36)$ & 0.676 \\
\hline \multicolumn{6}{|c|}{ Someone close diagnosed with cancer? } \\
\hline No & 57.7 (45) & 1.00 & & & \\
\hline Yes & $60.2(80)$ & $0.90(0.42-1.94)$ & 0.727 & & \\
\hline \multicolumn{6}{|c|}{ Someone close diagnosed with cervical cancer? } \\
\hline No & $58.8(114)$ & 1.00 & & & \\
\hline Yes & $64.7 \quad(11)$ & $1.29(0.71-2.33)$ & 0.303 & & \\
\hline \multicolumn{6}{|l|}{ Smoking status } \\
\hline No & $60.0(111)$ & 1.00 & & & \\
\hline Yes & $55.6(15)$ & $0.83(0.25-2.80)$ & 0.694 & & \\
\hline \multicolumn{6}{|l|}{ Entitled to EMA? } \\
\hline No (high-income household) & $60.9(81)$ & 1.00 & & & \\
\hline Yes (low-income household) & 59.7 (46) & $0.90(0.51-1.59)$ & 0.624 & & \\
\hline \multicolumn{6}{|l|}{ Sexually active } \\
\hline No & 57.1 (76) & 1.00 & & & \\
\hline Yes & $64.5(49)$ & $1.41(0.37-5.37)$ & 0.513 & & \\
\hline \multicolumn{6}{|l|}{ Age of sexual debut } \\
\hline 16 years and above & $62.9 \quad(22)$ & 1.00 & & & \\
\hline 15 years and below & $65.9(27)$ & $1.16(0.81-1.65)$ & 0.221 & & \\
\hline \multicolumn{6}{|l|}{ Intention to have the HPV vaccine } \\
\hline High & $64.6(104)$ & 1.00 & & & \\
\hline Low & $45.3 \quad(24)$ & $0.45(0.25-0.82)$ & 0.021 & $0.87 \quad(0.41-1.82)$ & 0.617 \\
\hline \multicolumn{6}{|l|}{ Continuous variables } \\
\hline HPV knowledge & & $1.09(1.02-1.16)$ & 0.027 & $1.00 \quad(0.90-1.12)$ & 0.964 \\
\hline Positive vaccine attitude & & $1.06(0.98-1.15)$ & 0.109 & & \\
\hline Needle fear & & $0.97(0.82-1.15)$ & 0.676 & & \\
\hline Parental acceptance & & $1.73(1.51-1.98)$ & $<0.001$ & $1.16 \quad(0.92-1.46)$ & 0.150 \\
\hline \multicolumn{6}{|l|}{ Normative beliefs about the vaccine } \\
\hline Friends & & $1.38(1.06-1.79)$ & 0.027 & $0.89(0.48-1.65)$ & 0.630 \\
\hline Parents & & $1.56(1.18-2.06)$ & 0.012 & $1.05 \quad(0.76-1.45)$ & 0.680 \\
\hline Vaccine safety & & $1.54(1.18-2.00)$ & 0.010 & $1.13(0.94-1.36)$ & 0.143 \\
\hline \multicolumn{6}{|l|}{ Vaccine effectiveness against: } \\
\hline HPV & & $1.48(0.92-2.38)$ & 0.083 & & \\
\hline Cervical cancer & & $1.92(1.02-3.62)$ & 0.046 & $1.58 \quad(0.96-2.61)$ & 0.064 \\
\hline Sexually transmitted infections & & $0.92(0.79-1.07)$ & 0.208 & & \\
\hline
\end{tabular}




\begin{tabular}{|c|c|c|c|c|c|}
\hline \multirow[b]{2}{*}{ Variables } & \multirow[b]{2}{*}{ Vaccine initiated $[\%(n)]$} & \multicolumn{2}{|c|}{ Uni-variable analyses* } & \multicolumn{2}{|c|}{$\begin{array}{l}\text { Multi-variable analysis } \\
(n=204)^{*}\end{array}$} \\
\hline & & OR $(95 \% \mathrm{Cl})$ & $p$ & OR $(95 \% \mathrm{Cl})$ & $p$ \\
\hline \multicolumn{6}{|l|}{ Perceived severity of: } \\
\hline HPV & & $1.07(1.02-1.12)$ & 0.021 & $1.02(0.89-1.17)$ & 0.703 \\
\hline Cervical cancer & & $1.19(0.98-1.44)$ & 0.065 & & \\
\hline \multicolumn{6}{|l|}{ Perceived susceptibility to: } \\
\hline HPV & & $1.50(1.26-1.78)$ & 0.003 & $1.29(0.95-1.75)$ & 0.080 \\
\hline Cervical cancer & & $1.33(0.90-1.96)$ & 0.116 & & \\
\hline Discussing sex with parents & & $1.07(0.79-1.44)$ & 0.576 & & \\
\hline
\end{tabular}

* Note that $n$ varies between analyses because of missing data.

$\mathrm{Cl}$, confidence interval; EMA, Education Maintenance Allowance; HPV, human papillomavirus; OR, odds ratio.

dose in $2009 / 2010 .{ }^{4}$ The slightly higher coverage in our sample is likely to be due to the fact that our respondents were all in full-time education. Girls not in education had to access the 'catch-up' vaccine through primary care, where uptake is known to be lower. $^{3}$

Despite the significant relationship between intention and behaviour, when other factors were taken into account (notably girls' ethnicity), intention no longer predicted behaviour. The difference between the uni- and multi-variable findings suggests that other factors play a more important role than intentions in vaccination behaviour. Girls may believe that receiving the vaccine sounds like the right thing to do (i.e. they intend to do so) in principle, but their cultural values and perhaps other factors not measured in our study are stronger predictors of actual behaviour.

Our findings differ from those of Gerend and Shepherd ${ }^{15}$ who found that intention predicted whether 18-26-year-old girls received the HPV vaccine 10 months later in a multi-variable model. However, this model did not include girls' ethnicity so the findings may not be directly comparable. In addition, it seems plausible that intention would be more important in predicting uptake when the vaccine must be actively sought in a health care setting, unlike the UK situation where HPV vaccination is offered in schools, so less effort is required on the part of the individual.

\section{Study limitations}

The study examined girls who were eligible to receive the HPV vaccination as part of the UK 'catch-up' cohort. These girls were old enough to provide their own consent to vaccination, unlike girls from the routine vaccination programme, and so the results may not be wholly generalisable to girls in the routine cohort where parental factors are likely to play a more influential role. However, it is likely that parents will include their daughters in their vaccination decisions ${ }^{41}$ so girls' beliefs about vaccination are an important factor to consider. It seems unlikely that 12 13-year-old girls' beliefs about HPV vaccination would differ considerably from those of girls aged 16-18 years, but this is an interesting area for future research.

All the girls were recruited from further education colleges and so the results may not be generalisable to the whole 'catch-up' population. The sample size was significantly reduced at follow-up and certain demographic groups were less likely to be included at follow-up (notably participants from a Black ethnic background) which may have biased the results. However, we believe that significant bias is improbable as the reasons that girls did not participate at follow-up are unlikely to be related to their baseline responses or their decision to receive the vaccine or not; girls did not participate at follow-up because their college chose not to be involved with the research again or because the girl was not in college on the day of data collection or had left the college.

Furthermore, while some of the estimated ORs are substantial, these failed to reach statistical significance as indicated by the large CIs (Table 2). Due to the sample size, the current study is only powered to detect large effects, and further research is needed to investigate variables with moderate effect sizes. Vaccination status relied on self-report and focused on initiation, rather than completion of the three-dose course. An important avenue for future research may be to consider the predictors of completion of the vaccination course.

\section{CONCLUSIONS}

Future research investigating predictors of vaccine uptake among girls from ethnic minority groups may aid an understanding of uptake among non-white populations in the UK.

Acknowledgement The authors are grateful to Dr Ellen van Jaarsveld for her statistical advice.

Funding The study was funded by a UCL Dean's Studentship; the sponsors had no other involvement in the study. Harriet 
Bowyer, Jo Waller and Laura Marlow are funded by Cancer Research UK.

\section{Competing interests None.}

Ethics approval The study was approved by University College London Research Ethics Committee.

Provenance and peer review Not commissioned; externally peer reviewed.

Open access This is an Open Access article distributed in accordance with the Creative Commons Attribution Non Commercial (CC BY-NC 3.0) license, which permits others to distribute, remix, adapt, build upon this work noncommercially, and license their derivative works on different terms, provided the original work is properly cited and the use is non-commercial. See: http://creativecommons.org/licenses/by$\mathrm{nc} / 3.0 /$

\section{REFERENCES}

1 Schiffman M, Castle PE, Jeronimo J, et al. Human papillomavirus and cervical cancer. Lancet 2007;370:890-907.

2 Munoz N, Bosch FX, Castellsague X, et al. Against which human papillomavirus types shall we vaccinate and screen? The international perspective. Int J Cancer 2004;111:278-285.

3 Department of Health. Annual HPV vaccine uptake in England: 2008/9. http://www.dh.gov.uk/prod_consum_dh/ groups/dh_digitalassets/@dh/@en/@ps/documents/digitalasset/ dh_111676.pdf [accessed 9 October 2012].

4 Department of Health. Annual HPV vaccine coverage in England in 2009/2010. http://www.dh.gov.uk/prod_consum _ $\mathrm{dh} /$ groups/dh_digitalassets/documents/digitalasset/dh_123826. pdf [accessed 9 October 2012].

5 Cuzick J, Castanon A, Sasieni P. Predicted impact of vaccination against human papillomavirus 16/18 on cancer incidence and cervical abnormalities in women aged 20-29 in the UK. Br J Cancer 2010;102:933-939.

6 Sturm LA, Mays RM, Zimet GD. Parental beliefs and decision making about child and adolescent immunization: from polio to sexually transmitted infections. J Dev Beh Pediatr 2005;26:441-452.

7 Rosenstock IM. Why people use health services. Milbank Mem Fund Q Health Soc 1966;44:94-127.

8 Ajzen I. The theory of planned behavior. Organ Behav Hum Decis Process 1991;50:179-211.

9 Brewer NT, Fazekas KI. Predictors of HPV vaccine acceptability: a theory-informed, systematic review. Prev Med 2007;45:107-114.

10 Bennett KK, Buchanan JA, Adams AD. Social-cognitive predictors of intention to vaccinate against the human papillomavirus in college-age women. J Soc Psychol 2012;152:480-492.

11 Marlow LAV, Waller J, Evans REC, et al. Predictors of interest in HPV vaccination: a study of British adolescents. Vaccine 2009;27:2483-2488.

12 Di Giuseppe G, Abbate R, Liguori G, et al. Human papillomavirus and vaccination: knowledge, attitudes, and behavioural intention in adolescents and young women in Italy. Br J Cancer 2008;99:225-229.

13 Kahn JA, Rosenthal SL, Jin Y, et al. Rates of human papillomavirus vaccination, attitudes about vaccination, and human papillomavirus prevalence in young women. Obstet Gynecol 2008;111:1103-1110.

14 Juraskova I, Bari RA, O’Brien MT, et al. HPV vaccine promotion: does referring to both cervical cancer and genital warts affect intended and actual vaccination behavior? Womens Health Issues 2011;21:71-79.

15 Gerend MA, Shepherd JE. Predicting HPV vaccine uptake in young adult women: comparing the health belief model and theory of planned behavior. Ann Behav Med 2011;41:S256.

16 Patel DA, Zochowski M, Peterman S, et al. Human papillomavirus vaccine intent and uptake among female college students. J Am Coll Health 2012;60:151-161.

17 Conroy K, Rosenthal SL, Zimet GD, et al. Human papillomavirus vaccine uptake, predictors of vaccination, and self-reported barriers to vaccination. J Womens Health 2009;18:1679-1686.

18 de Visser R, Waites L, Parikh C, et al. The importance of social norms for uptake of catch-up human papillomavirus vaccination in young women. Sex Health 2011; 8:330-337.

19 Bynum SA, Brandt HM, Sharpe PA, et al. Working to close the gap: identifying predictors of HPV vaccine uptake among young African American women. J Health Care Poor Underserved 2011;22:549-561.

20 Reiter PL, Brewer NT, Gottlieb SL, et al. Parents' health beliefs and HPV vaccination of their adolescent daughters. Soc Sci Med 2009;69:475-480.

21 Brewer NT, Gottlieb SL, Reiter PL, et al. Longitudinal predictors of human papillomavirus vaccine initiation among adolescent girls in a high-risk geographic area. Sex Transm Dis 2011;38:197-204.

22 Mcree AL, Reiter PL, Gottlieb SL, et al. Mother-daughter communication about HPV vaccine. J Adolesc Health 2011;48:314-317.

23 Roberts ME, Gerrard M, Reimer R, et al. Mother-daughter communication and human papillomavirus vaccine uptake by college students. Pediatrics 2010;125:982-989.

24 Forster AS, Marlow LA, Wardle J, et al. Understanding adolescents' intentions to have the HPV vaccine. Vaccine 2010;28:1673-1676.

25 Sheeran P, Abraham C. Mediator of moderators: temporal stability of intention and the intention-behavior relation. Pers Soc Psychol Bull 2003;29:205-215.

26 Wellings K, Nanchahal K, Macdowall W, et al. Sexual behaviour in Britain: early heterosexual experience. Lancet 2001;358:1843-1850.

27 Waller J, Ostini R, Marlow LA, et al. Validation of a measure of knowledge about human papillomavirus (HPV) using item response theory and classical test theory. Prev Med 2012; 56:35-40.

28 Davis K, Dickman ED, Ferris D, et al. Human papillomavirus vaccine acceptability among parents of 10 - to 15 -year-old adolescents. J Low Genit Tract Dis 2004;8:188-194.

29 Armitage CJ, Conner M. Predictive validity of the theory of planned behaviour: the role of questionnaire format and social desirability. J Community Appl Soc Psychol 1999; 9:261-272.

30 Witte K, Cameron KA, McKeon JK, et al. Predicting risk behaviors: development and validation of a diagnostic scale. J Health Commun 1996;1:317-341.

31 Marlow LAV, Waller J, Wardle J. Parental attitudes to pre-pubertal HPV vaccination. Vaccine 2007;25:1945-1952.

32 Weinstein ND, Kwitel A, McCaul KD, et al. Risk perceptions: assessment and relationship to influenza vaccination. Health Psychol 2007;26:146-151.

33 Hutchinson MK, Jemmott JB, Jemmott LS, et al. The role of mother-daughter sexual risk communication in reducing sexual 
risk behaviors among urban adolescent females: a prospective study. J Adolesc Health 2003;33:98-107.

34 IBM. SPSS Statistics for Windows (Version 20.0). IBM Corporation, Armonk, NY, USA. http://www-01.ibm.com/ software/uk/analytics/spss/ [accessed 9 October 2012].

35 Kumar VM, Whynes DK. Explaining variation in the uptake of HPV vaccination in England. BMC Public Health 2011;11:172.

36 Kessels SJM, Marshall HS, Watson M, et al. Factors associated with HPV vaccine uptake in teenage girls: a systematic review. Vaccine 2012;30:3546-3556.

37 Fisher H, Trotter CL, Audrey S, et al. Inequalities in the uptake of human papillomavirus vaccination: a systematic review and meta-analysis. Int J Epidemiol 2013; doi:10.1093/ije/dyt049.
38 Brabin L, Roberts SA, Stretch R, et al. Uptake of first two doses of human papillomavirus vaccine by adolescent schoolgirls in Manchester: prospective cohort study. BMJ 2008;336:1056-1058.

39 Roberts SA, Brabin L, Stretch R, et al. Human papillomavirus vaccination and social inequality: results from a prospective cohort study. Epidemiol Infect 2011;139:400-405.

40 Marlow LAV. HPV vaccination among ethnic minorities in the UK: knowledge, acceptability and attitudes. Br J Cancer 2011;105:486-492.

41 Brabin L, Roberts SA, Stretch R, et al. A survey of adolescent experiences of human papillomavirus vaccination in the Manchester study. Br J Cancer 2009;101:1502-1504.

\section{Peer reviewers 2013}

The Editorial Team would like to thank the individuals listed below who generously gave their time and expertise in acting as peer reviewers for the Journal in 2013.

\begin{tabular}{|c|c|}
\hline Abdala, Nadia & Connor, Mary \\
\hline Adam, Sheila & Crook, Angela \\
\hline Afolabi, Ebenezer & Crook, David \\
\hline Agampodi, Suneth & Cuschieri, Kate \\
\hline Andreadis, Natasha & Darlow, Kate \\
\hline Bacon, Lesley & de Silva, Shamela \\
\hline Bahamondes, Luis & Dempsey, Deborah \\
\hline Baird, Aisling & Devonald, Elizabeth \\
\hline Barber, Tristan & Dickson, Jane \\
\hline Beddard, Stuart & Dinger, Juergen \\
\hline Bell, David & Dodge, Laura \\
\hline Bentley, Janet & Downing, Jordan \\
\hline Best, Candace & Draper, Isabel \\
\hline Bowyer, Harriet & Duncan, Margaret \\
\hline Box, Matthew & Dunn, Sheila \\
\hline Bradbeer, Caroline & Edouard, Lindsay \\
\hline Briggs, Paula & Elliman, Alyson \\
\hline Brin, Genevieve & Everett, Marian \\
\hline Brotherton, Julia & Everett, $\mathrm{Su}$ \\
\hline Brown, Katherine & Finocchario-Kessler, \\
\hline Brown, Sally & Sarah \\
\hline Bumpstead, Ewan & Flett, Gillian \\
\hline Burden, Helena & Forcier, Michelle \\
\hline Bussey, Angela & Forrest, Simon \\
\hline Cameron, Sharon & Franks, Stephen \\
\hline Campbell, Martha & Fraser, Ian \\
\hline Carlin, Elizabeth & French, Rebecca \\
\hline Carmona, Francisco & Furedi, Ann \\
\hline Church, Kathryn & Gatiss, Sarah-Jane \\
\hline Clark, Caroline & Gebbie, Ailsa \\
\hline Clarke, Jan & Gerressu, Makeda \\
\hline Cochrane, Rosemary & Gibbon, Marion \\
\hline Coffee, Andrea & Glasier, Anna \\
\hline Coffey, Patricia & Griffiths, Megan \\
\hline Connolly, Anne & Haddad, Lisa \\
\hline
\end{tabular}

Hagos, Amanue

Hamoda, Haitham

Heathcote, Jennifer

Hicks, Stephen

Hillard, Tim

Hinde, Andrew

Hinson, Laura

Hogston, Patrick

Husemeyer, Roy

Iantaffi, Alex

Ingham, Roger

Jensen, Jeffery

Jones, Kenneth

Jones, Rachel

Kane, Ros

Kavanagh, Jayne

Kay, Vanessa

Kilbourne-Brook,

Maggie

Kingston, Margaret

Kosimbei, George

Kulczycki, Andrzej

Lee, Ellie

Lyons, Deirdre

Mann, Melanie

Mann, Susan

Mansour, Diana

Massey, Louise

McClure, Myra

McGough, Pauline

McKay, Rebecca

McRee, Annie-Laurie

Melvin, Louise

Menon, Ken

Mesher, David
Michie, Lucy

Moen, Mette

Mogos, Mulubrhan

Moore, Erin

Mueck, Alfred

Mullin, Nicola

Murphy, Dean

Nelson, Anita

Neubert, Antje

Ohizua, Omi

Olowookere, Samuel

Oscarsson, Marie

Panay, Nick

Parkin, Donald

Penman Aguilar, Anna

Piantelli, Giovanni

Pickard, Sally

Pillai, Mary

Potts, Malcolm

Quilliam, Susan

Radhakrishnan, Sheila

Reed, Craig

Reid, Robert

Reiter, Paul

Ribbans, Helen

Riggs, Damien

Rogstad, Karen

Romanowski, Barbara

Rosenthal, Adam

Rowlands, Sam

Salazar, Mariano

Sasieni, Peter

Sathiya Susuman, Appunni

Sayem, Amir

Serrant-Green, Laura
Shapiro, Samuel

Sharma, Suresh

Shawe, Jill

Sheldon, Sally

Shreffler, Karina

Shulman, Lee

Singh, Abhishek

Singh, Hari

Soshnikov, Sergey

Stephens, Liz

Stuart, Beth

Sulak, Patricia

Sunkara, Sesh

Tenkku, Leigh

Terplan, Mishka

Trewinnard, Karen

Trichopoulous, Dimitrios

Tristram, Amanda

Trussell, James

van Teijlingen, Edwin

Vanhegan, Gillian

Walker, Susan

Waller, Jo

Webb, Anne

Weeks, Andrew

Weisberg, Edith

Welsh, Val

Westley, Elizabeth

Wilkins, David

Worsley, Roisin

Yam, Eileen

Zelin, Jill 